\title{
Basics of Peripheral Nerve Injury Rehabilitation
}

\author{
Reza Salman Roghani ${ }^{1}$ and Seyed Mansoor Rayegani² \\ ${ }^{1}$ University of Social Welfare and Rehabilitation, Tehran, \\ 2Shahid Beheshti University of Medical Science, Tehran,
}

Iran

\section{Introduction}

The study of peripheral nerve injury, repair \& rehabilitation began during the American Civil War and has since expanded to not only include to extensive characterization of the processes and factors that contribute to nerve regeneration and reinnervation, but also to determining therapies that enhance nerve regeneration such as physical modalities, rehabilitation consideration and recently biological conduits and administration of growth promoting molecules.[1] Rehabilitation medicine is a branch of medicine that aims to enhance and restore functional ability and quality of life to those with physical impairments or disabilities. Functional disability due to nerve lesions is completely related to the severity, type and location of nerve lesions. So, before starting any rehabilitation program for patients with nerve injury, deep knowledge of lesion's type and denervation consequences is necessary.

\section{Peripheral nerve injury classification}

Classification of peripheral nerve injury has an important role in prognosis prediction and treatment strategy determination. Classification of nerve injury was described by Seddon in 1943 and by Sunderland in 1951. In brief it classified to mild, moderate and severe injuries resembling pathologic terms of neurapraxia, axonotmesis and neurotmesis consequently. In the first one the nerve remains intact but signaling ability is damaged, in the second degree the axon is damaged but the surrounding connective tissue remains intact and in the last one both the axon and connective tissue are damaged. $[2,3]$ the most common etiology for these three types of injury is entrapment neuropathies, blunt and sharp trauma consequently.

\section{Peripheral nerve injury consequences}

The effects of peripheral nerve injuries are vary depending on the cause and severity of the injury. These are Pain (ranging from a tingling to intense burning pain), numbness or altered sensations, muscle weakness in the affected body part, loss of function (eg. a hand or leg being difficult to use whilst performing tasks), Loss of active movement (eg. wrist drop and foot drop) joint stiffness and skin sores and finally emotional stress. 


\section{Rehabilitation medicine in brief}

Rehabilitation medicine in nerve injuries is a non surgical, comprehensive management of injury consequences, controlling positive disturbing symptoms such as pain, preventing long term deformities such as contractures and utilizing proper techniques and modalities to enhance nerve repair and recovery. Following we will discuss the program in detail.

\section{Pain management}

Pain is one of the most common and annoying consequences of nerve damage. For the first time massive spontaneous discharges was reported in L4 and 5 dorsal rootlets after producing an experimental sciatic nerve lesion of a rabbit. Since then many mechanisms proposed as the etiology of neuropathic pain but the most recent and acceptable one is dramatic and robust chemical changes occurring in dorsal root ganglions after peripheral nerve damage, which is a new generator and presumably contribute in the process of neuropathic pain. There are also other mechanisms in dorsal column of cord and brain which are proposed as contributors to neuropathic pain. This pain management is an interdisciplinary approach centered by pharmacological treatments.[4] New treatment strategies for neuropathic pain are mainly invented considering the changes in central nervous system. [5] Anticonvulsants and tri-cyclic anti depressants are the most popular drugs for neuropathic pain.[6] Complete relief is very difficult and only $40-60 \%$ of patients achieves partial relief. [7] Other modalities which have some role in neuropathic pain management are yoga, massage, meditation, cognitive exercise, acupuncture and Transcutaneous electrical nerve stimulation (TENS). [8]

\section{Sensation deficit and relearning}

Body image, objects' shape and texture recognition and avoiding hazardous objects are the principles roles of an intact sensation. Sensory stimuli are also send a feedback to motor system for proper adjustment in function. Contra lateral somatosensory cortex play as a central processing unit for almost all of these functions. Following a peripheral nerve injury one or all of above mentioned functions may be impaired based on the severity of insult. Complete injury of a major nerve or its sensory part turns off related contra lateral somatosensory cortex until reinnervation or repair is occurred. In this scene all of five principles sensory functions being impaired. If reinnervation occurs in a disorganized pattern the sensory cortex faced a new pattern of input which is usually unknown. This is the basis of sensory rehabilitation or re-familiarization even with a successful surgical nerve repair. Shape and texture relearning with open eye and stimulating deep receptor by rough objects are helpful methods of proper reorganization [fig1]. (Rosén et al., 2003; Lundborg, 2004) large nerves injury such as sciatic in lower extremities' nerve and also more widespread nerve lesions such as neuropathies have a profound effect on all sensation and motor related functions but proprioception is one of the most important one. Proprioception is defined as sensing the body movements and awareness of posture, enabling the person to orient itself in space without visual clues.[9] Proprioception is what allows someone to walk in complete darkness or driving with only looking the road without losing balance or control. During the learning of any new skills or relearning old one such as a sport activity, 
or an art, it is usually necessary to become familiar with some proprioceptive tasks specific to that activity.

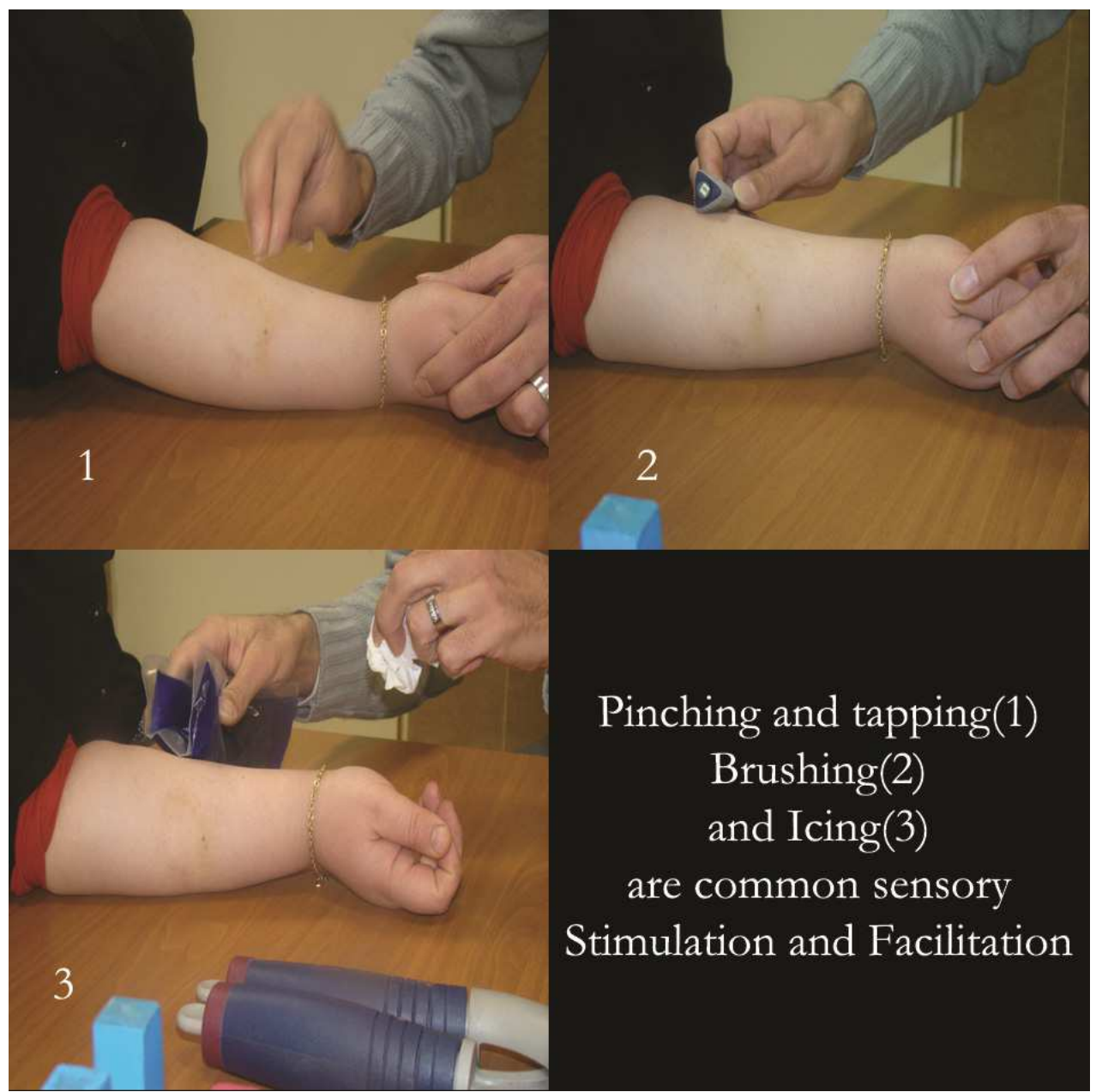

Fig. 1. Sensory stimulation and facilitation by Reza S Roghani, Rehabilitation University, Tehran, Iran

The proprioceptive sense can be sharpened through Juggling trains reaction time, spatial location, and efficient movement. Standing on a balance board is often used to retrain or increase proprioception abilities, particularly as physical therapy for ankle, knee and its nerve injuries. Advanced balance abilities which are used usually for athletes following nerve repair could be achieved by Yoga, Wing Chun and Tai-chi . There are even specific devices designed for proprioception training, such as the exercise ball, which works on balancing the abdominal and back muscles which may be impaired in nerve's root injuries. [10, 11] 


\section{Muscle weakness}

Major peripheral nerve injuries are usually leading to severe muscle atrophy and significant functional deficits. The neuromuscular junction undergoes significant changes after nerve injury and is the most critical point for functional recovery even after proper nerve regeneration .[12] Several methods are proposed for functional recovery and prevent muscle wasting. One of them is electrical stimulation which has a great controversy regarding beneficial effects in nerve regrowth [13] or diminish the speed and accuracy of reinnervation. [14] Another modality, is low level laser therapy or phototherapy which has promising effects in nerve re growth.[15] Muscle care following nerve injury is essential and includes protection against cold and heat exposures, minor trauma and overstretching by gravity. The key point is keeping muscles in a normal physiological length to prevent vascular and lymphatic stasis, contractures, and joint stiffness. Modalities which have significant role to achieve above goals are warmth, massage and passive movements, bandaging, ultrasound therapy, hydrotherapy and splints.

Static and detachable splints [fig2] is useful mechanical devices to give rest to the paralyzed muscles and joints, preventing overstretching and shortening and to allow exercises and other therapeutic methods to be given regularly for preventing complications of continued immobilization.[16]

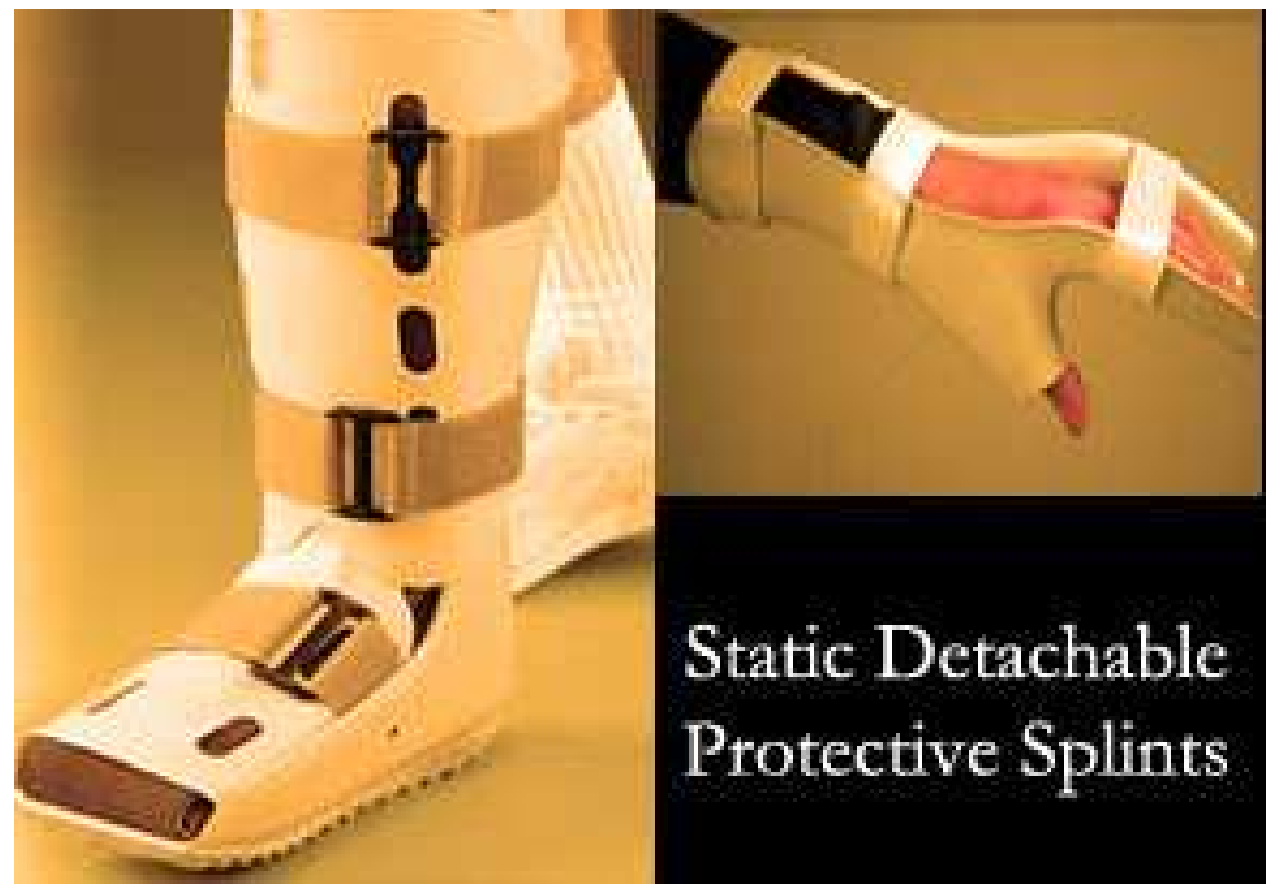

Fig. 2. Static and detachable splints by Reza S Roghani, Rehabilitation University, Tehran, Iran 


\section{Loss of function}

Functional loss is a direct effect of sensory and motor deficit following nerve injury. cortical sensory synaptic changes due to miss stimulation of peripherals, starting immediately after nerve injury leads to remapping of central sensory system makes re learning and proper functional recovery difficult. New trends in nerve injury rehabilitation focus on manipulation of central nervous processes rather than peripheral factors. Using the brain capacity for Visio-tactile and audio-tactile interaction and fine motor relearning [fig3] is the main concept for maintaining sensory cortex and periphery relationship in the initial phase following nerve injury and repair. After initiation of nerve re-growth, anesthesia of intact peripheral skin with topical agents especially during sensory relearning sessions is a new method to prevent early changes until sensory recovery completes and relearning process made possible. [17, 18] another issue in proper functional recovery is neuromuscular junction instability immediately after denervation which is hard to stabilized properly even after repair and complete regeneration. It is more present in more complex and fine tasks. Rehabilitation protocols that focus on relearning programs of fine tasks address this issue and increase the chance of functional outcome improvement after nerve repair. [18]

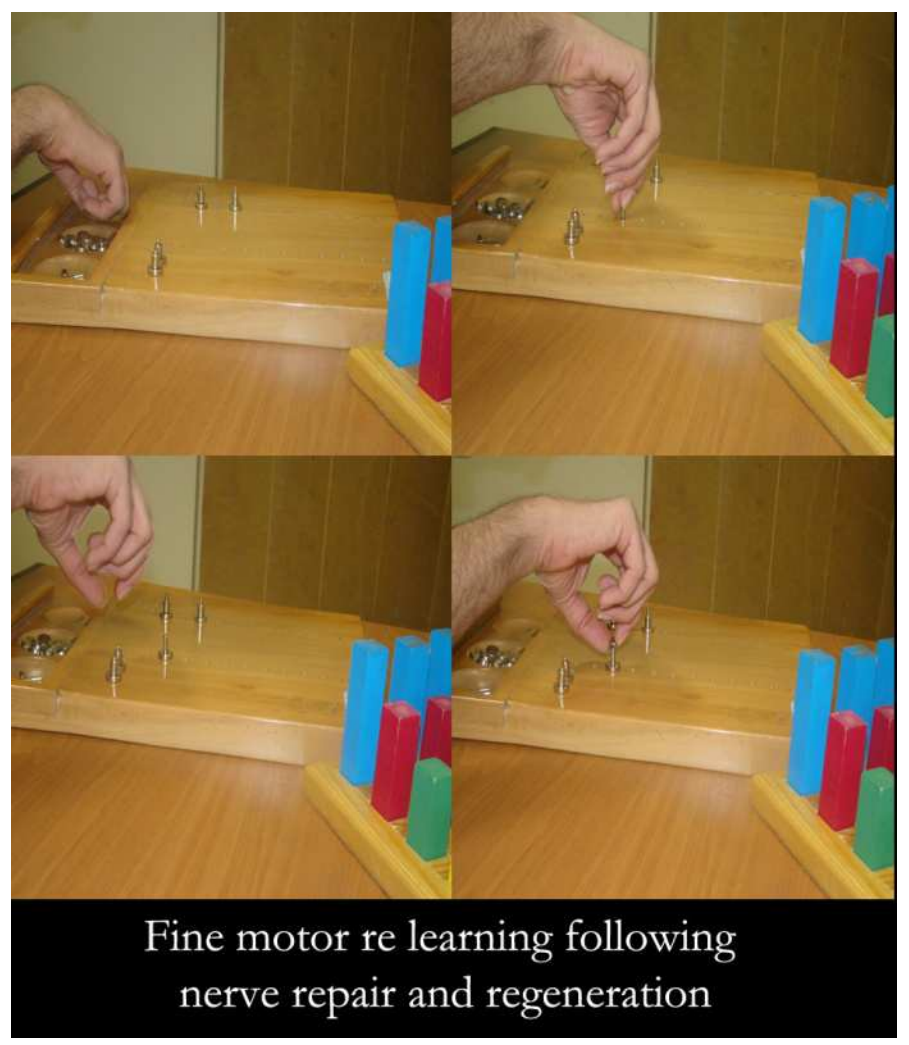

Fig. 3. Fine motor re learning following nerve repair and regeneration by Reza S Roghani, Rehabilitation University, Tehran, Iran 


\section{Joint stiffness}

The insensitive joints and ligaments and other surrounding tissues which are affected by the injury to all or some supplying nerves are at the risk of stiffness, shortening and finally contracture. Regular daily massage, passive motion in full range at least one time per day and protective detachable static splints could prevent these complications. In case of joint stiffness dynamic splints and physical modalities such as ultrasound and laser [Fig4] will help to regain the softening and range of motion. [19]

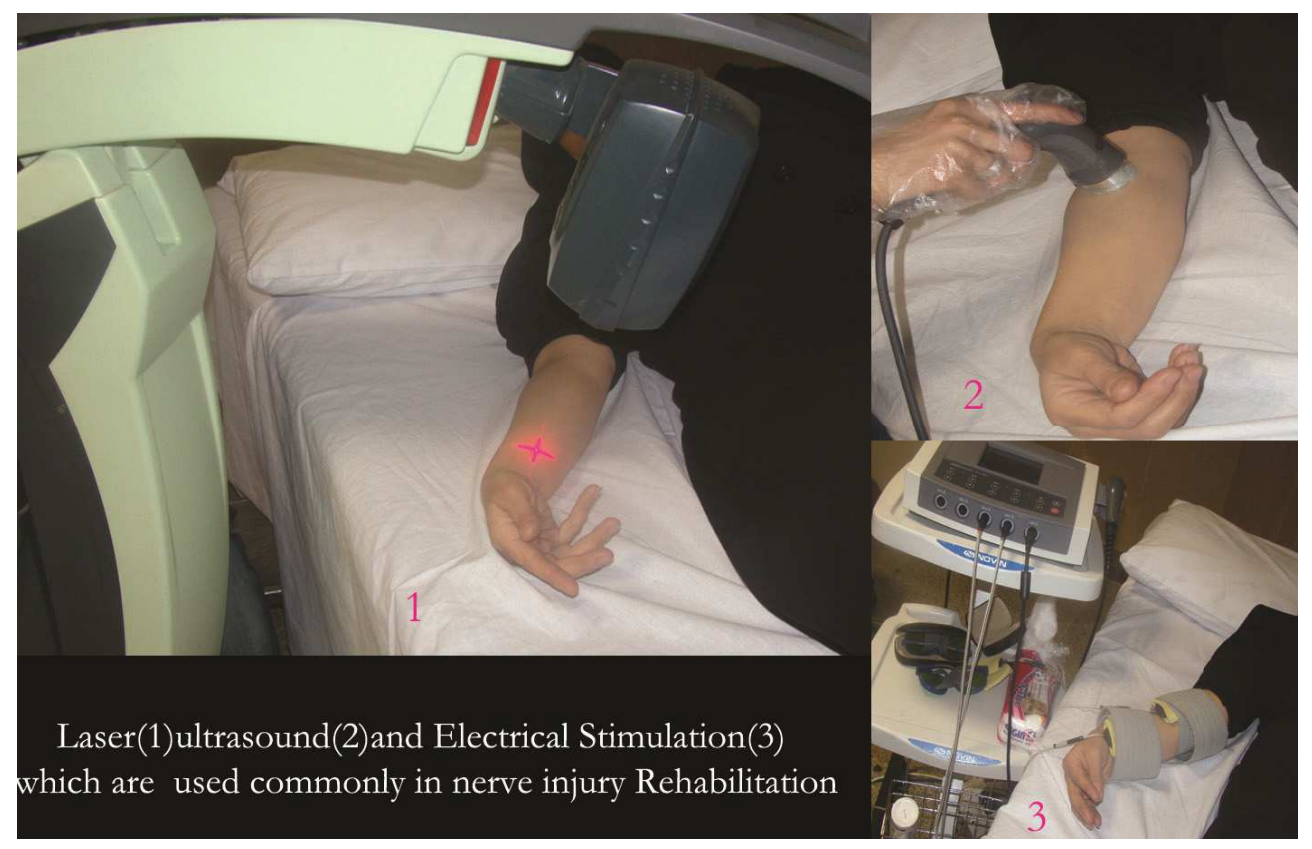

Fig. 4. Common modalities in nerve injury rehabilitation by Reza S Roghani, Rehabilitation University, Tehran, Iran

\section{Care of denervated skin}

Proper hot and sharp objects handling, take care of nails, avoiding long term cold weather exposure, and well padded splints use are the corner stone of denervated skin care. Skin also should be cleaned with mild soap and warm water and gently patted dry. Locations is vulnerable to excess moisture can be protected with talcum powder and too dry area should have lotion applied. Direct or using a mirror for daily skin inspection is important to identify vulnerable areas for sores such as high pressure points under splints.[20]

\section{Emotional stress}

Severe pain and paralysis accompanying nerve injury usually lead to cognitive problem; sleep disorder and anxiety reduce quality of life and hamper efficient medical treatment. [21] Alteration of extracellular glycine concentration in related spinal cord and brain cortex 
develop mechanical hypersensitivity after peripheral nerve injury may exhibit impaired recognition ability and may be the main mechanism of long lasting pain and a source of emotional stress. If it is not addressed properly and as soon as possible it may lead to chronic hippocampal plasticity and develop chronic pain.[22] Cognitive rehabilitation programs would address mood disturbance, enhance functional outcome and also prevent or decline chronic pain following nerve injury and repair. [23]

\section{References}

[1] Campbell, W.W., Evaluation and management of peripheral nerve injury. Clinical Neurophysiology, 2008. 119: p. 1951-1965.

[2] Sunderland, S., A classification of peripheral nerve injuries producing loss of function. Brain, 1951. 74: p. 491-516.

[3] Seddon, H., Three types of nerve injuries. Brain, 1943. 66: p. 237.

[4] Hökfelt, T., et al., eds. Central consequences of peripheral nerve. Neuropathic pain. 2005.

[5] Baron, R., A. Binder, and G. Wasner, Neuropathic pain: diagnosis, pathophysiological mechanisms, and treatment. Lancet Neurol, 2010. 9(8): p. 807-19.

[6] Selph, S., et al., Drug Class Review: Neuropathic Pain. 2011.

[7] O'Connor, A.B. and R.H. Dworkin, Treatment of neuropathic pain: an overview of recent guidelines. Am J Med, 2009. 122(10 Suppl): p. S22-32.

[8] Yameen, F., et al., Efficacy of transcutaneous electrical nerve stimulation and its different modes in patients with trigeminal neuralgia. J Pak Med Assoc, 2011. 61(5): p. 437-9.

[9] Mosby, properioception 8th edition ed. Medica Dictionary. 2009: elsevier.

[10] Salsabili, H., et al., Dynamic stability training improves standing balance control in neuropathic patients with type 2 diabetes. J Rehabil Res Dev, 2011. 48(7): p. 775-86.

[11] Bullinger, K.L., et al., Permanent central synaptic disconnection of proprioceptors after nerve injury and regeneration. II. Loss of functional connectivity with motoneurons. J Neurophysiol, 2011. 106(5): p. 2471-85.

[12] Kang, J.R., D.P. Zamorano, and R. Gupta, Limb salvage with major nerve injury: current management and future directions. J Am Acad Orthop Surg, 2011. 19 Suppl 1: p. S2834.

[13] Gordon, T., O.A. Sulaiman, and A. Ladak, Chapter 24: Electrical stimulation for improving nerve regeneration: where do we stand? Int Rev Neurobiol, 2009. 87: p. 433-44.

[14] Gigo-Benato, D., et al., Electrical stimulation impairs early functional recovery and accentuates skeletal muscle atrophy after sciatic nerve crush injury in rats. Muscle Nerve, 2011. 41(5): p. 685-93.

[15] Rochkind, S., S. Geuna, and A. Shainberg, Chapter 25: Phototherapy in peripheral nerve injury: effects on muscle preservation and nerve regeneration. Int Rev Neurobiol, 2009. 87: p. 445-64.

[16] Campbell, W.W., Evaluation and management of peripheral nerve injury. Clin Neurophysiol, 2008. 119(9): p. 1951-65.

[17] Rosen, B. and G. Lundborg, Sensory re-education after nerve repair: aspects of timing. Handchir Mikrochir Plast Chir, 2004. 36(1): p. 8-12.

[18] Lundborg, G. and B. Rosen, Hand function after nerve repair. Acta Physiol (Oxf), 2007. 189(2): p. 207-17.

[19] Krosl, W., [To treat or prevent joint stiffness. (Problem of organization)]. Riv Infort Mal Prof, 1961. 48: p. 83-9. 
[20] Dealey, C., Skin care and pressure ulcers. Advances in Skin \& Wound Care, 2009. 22.

[21] Novak, C.B., et al., Biomedical and psychosocial factors associated with disability after peripheral nerve injury. J Bone Joint Surg Am, 2011. 93(10): p. 929-36.

[22] Kodama, D., H. Ono, and M. Tanabe, Increased hippocampal glycine uptake and cognitive dysfunction after peripheral nerve injury. Pain, 2011. 152(4): p. 809-17.

[23] Mahmoudaliloo, M., et al., The correlation of cognitive capacity with recovery of hand sensibility after peripheral nerve injury of upper extremity. NeuroRehabilitation, 2011. 29(4): p. 373-9. 


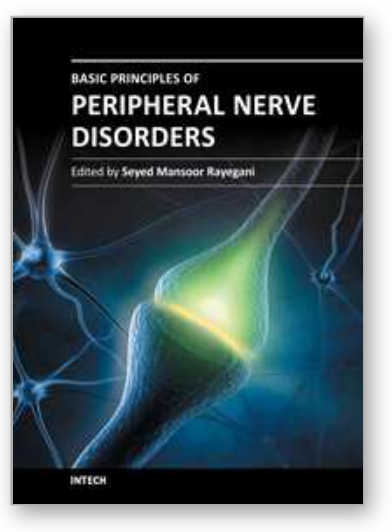

\author{
Basic Principles of Peripheral Nerve Disorders \\ Edited by Dr. Seyed Mansoor Rayegani
}

ISBN 978-953-51-0407-0

Hard cover, 278 pages

Publisher InTech

Published online 28, March, 2012

Published in print edition March, 2012

Peripheral nerve disorders are comprising one of the major clinical topics in neuromusculoskeletal disorders. Sharp nerve injuries, chronic entrapment syndromes, and peripheral neuropathic processes can be classified in this common medical topic. Different aspects of these disorders including anatomy, physiology, pathophysiology, injury mechanisms, and different diagnostic and management methods need to be addressed when discussing this topic. The goal of preparing this book was to gather such pertinent chapters to cover these aspects.

\title{
How to reference
}

In order to correctly reference this scholarly work, feel free to copy and paste the following:

Reza Salman Roghani and Seyed Mansoor Rayegani (2012). Basics of Peripheral Nerve Injury Rehabilitation, Basic Principles of Peripheral Nerve Disorders, Dr. Seyed Mansoor Rayegani (Ed.), ISBN: 978-953-51-0407-0, InTech, Available from: http://www.intechopen.com/books/basic-principles-of-peripheral-nervedisorders/basics-of-peripheral-nerve-injury-rehabilitation

\section{INTECH}

open science | open minds

\section{InTech Europe}

University Campus STeP Ri

Slavka Krautzeka 83/A

51000 Rijeka, Croatia

Phone: +385 (51) 770447

Fax: +385 (51) 686166

www.intechopen.com

\section{InTech China}

Unit 405, Office Block, Hotel Equatorial Shanghai

No.65, Yan An Road (West), Shanghai, 200040, China

中国上海市延安西路65号上海国际贵都大饭店办公楼405单元

Phone: +86-21-62489820

Fax: $+86-21-62489821$ 
(C) 2012 The Author(s). Licensee IntechOpen. This is an open access article distributed under the terms of the Creative Commons Attribution 3.0 License, which permits unrestricted use, distribution, and reproduction in any medium, provided the original work is properly cited. 